\title{
A Study on Mass Spectrometry of Methylated [60] Fullerenes Using the "In-beam" Electron Impact Technique
}

\author{
Hamad M. Al-Matar and Sayed M. Badawy \\ Chemistry Department, Faculty of Science, Kuwait University, Safat, Kuwait
}

Mass spectra of the methylated [60]fullerenes were obtained by EI mass spectrometry using "desorption" or "in-beam" technique. The mass spectra of the methylated fullerenes, $\mathrm{C}_{60} \mathrm{Me}_{\mathrm{n}}$, have the molecular ion peak $\mathrm{M}^{+}$indicating that the product is stable under the MS (EI) conditions. The appearance of an intense peak at $\mathrm{m} / \mathrm{z} 360$ was assigned to the formation of fullerene dication $\mathrm{C}_{60}^{++}$. The remaining peaks were assigned to successive loss of methyl groups from molecular monocation and dication. (J Am Soc Mass Spectrom 2005, 16, 1311-1315) (c) 2005 American Society for Mass Spectrometry

A lkylation involves reaction of fullerene anions with positive alkyl groups. This leads to different addition patterns, which vary also according to the alkylation technique. These compounds are exceptionally soluble fullerenes, and promise to be useful cross-linking additives, for which the parent fullerenes are too insoluble.

Their relative simplicity aids structural characterization, and many of them form suitable crystals for X-ray structure determination [1, 2]. Although the small size of the methyl group and the reasonable stability of the methylfullerenes toward electron impact (EI) mass spectrometry made the reaction suitable for elucidating mechanistic features of fullerene additions, the polymethylation was a disincentive to further work [3]. The availability of high-pressure liquid chromatography (HPLC) columns dedicated to fullerene separation has enabled progress to be made.

The methylated fullerenes were prepared in our previous works by different methods [1-4]: (1) reaction of fullerene with lithium followed by MeI, (2) reduction of fullerene with sodium $n$-propylthiolate followed by quenching with $\mathrm{MeI}$, (3) reduction of fullerene by $\mathrm{Al}-\mathrm{Ni}$ alloy and aqueous $\mathrm{NaOH}$-dimethyl sulfoxide followed by quenching with $\mathrm{MeI}$, and (4) methylation by nucleophilic substitution of halogenated fullerene $\mathrm{C}_{60} \mathrm{Cl}_{6}$. The resulting methylated fullerenes differ according to the method used, indicating different addition pathways:

Published online June 23, 2005

Address reprint requests to Dr. Hamad M. Al-Matar, Chemistry Department, Faculty of Science, Kuwait University, P.O. Box 5969, Safat, Kuwait. E-mail: almatar@kuc01.kuniv.edu.kw

$$
\begin{aligned}
& \mathrm{C}_{60} \underset{\mathrm{Mel}}{\mathrm{Li}} \underset{1,2-}{ } \text { and 1, 4- } \mathrm{C}_{60} \mathrm{Me}_{2}+\mathrm{C}_{60} \mathrm{Me}_{4}+\mathrm{C}_{60} \mathrm{Me}_{68} \\
& +\mathrm{C}_{60} \mathrm{Me}_{\mathrm{n}}(\mathrm{n}=8,10,12,14) \\
& \mathrm{C}_{60} \underset{\text { MeI }}{\stackrel{\mathrm{C}_{3} \mathrm{H}_{7} \mathrm{~S}-\mathrm{Na}^{+}}{\longrightarrow}} 1,2-\text { and 1, 4- } \mathrm{C}_{60} \mathrm{Me}_{2}+\mathrm{C}_{60} \mathrm{Me}_{4} \\
& +\mathrm{C}_{60} \mathrm{Me}_{5} \mathrm{H}+\mathrm{C}_{60} \mathrm{Me}_{3} \mathrm{OH} \\
& \mathrm{C}_{60} \underset{\text { MeI }}{\stackrel{\text { Al-Ni alloy }}{\longrightarrow}} 1,2-\text { and 1, 4- } \mathrm{C}_{60} \mathrm{Me}_{2}+\mathrm{C}_{60} \mathrm{Me}_{4}+\mathrm{C}_{60} \mathrm{Me}_{6} \text { (iii) } \\
& \mathrm{C}_{60} \underset{\text { Nu.Subst. }}{\stackrel{\mathrm{C}_{60} \mathrm{Cl}_{6}}{\longrightarrow}} \mathrm{C}_{60} \mathrm{Me}_{6}+\mathrm{C}_{60} \mathrm{Me}_{12}+\mathrm{C}_{60} \mathrm{Me}_{5} \mathrm{Cl} \\
& +\mathrm{C}_{60} \mathrm{Me}_{5} \mathrm{O}_{2} \mathrm{OH}+\mathrm{C}_{60} \mathrm{Me}_{5} \mathrm{OOH}+\mathrm{C}_{60} \mathrm{Me}_{5} \mathrm{O}_{3} \mathrm{H} \\
& +\mathrm{C}_{60} \mathrm{Me}_{4} \mathrm{PhO}_{2} \mathrm{OH}
\end{aligned}
$$

Separation of methylated fullerenes was performed with HPLC using a Cosmosil Buckyprep column with either heptane, toluene, toluene/heptane, or cyclohexane/toluene mixtures, with UV detection at $285 \mathrm{~nm}$ and a flow rate of $4 \mathrm{~mL} / \mathrm{min}$.

Mass spectra were obtained using a VG Autospec (Sussex University, UK) mass spectrometer using 70-eV EI ionization. The samples were introduced into the mass spectrometer using the direct insertion probe with desorption CI (chemical ionization) tip operated at a temperature between 50 and $500{ }^{\circ} \mathrm{C}$. The samples were coated on a surface and inserted directly inside an ion source, as close to the ionization area as possible, by means of an extended direct insertion probe. The "inbeam" technique gives a better chance of observing molecular ions in the mass spectra at the lower temperature and small sample size [5]. 

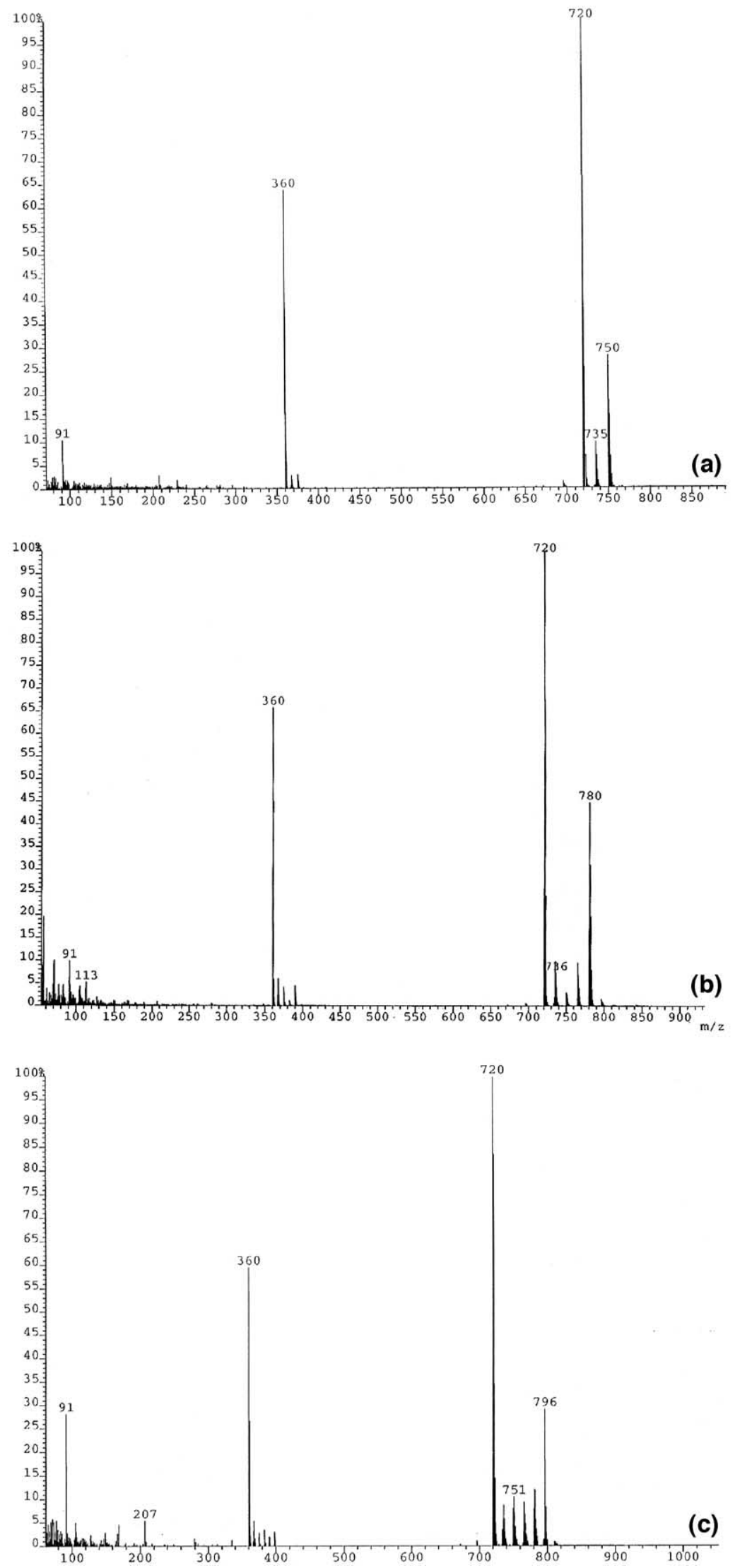

Figure 1. (a) EI mass spectra (70 eV, DCI probe) of $\mathrm{C}_{60} \mathrm{Me}_{2}$, (b) $\left(70 \mathrm{eV}\right.$, DCI probe) of $\mathrm{C}_{60} \mathrm{Me}_{4}$, (c) $(70$ $\mathrm{eV}$, DCI probe) of $\mathrm{C}_{60} \mathrm{Me}_{5} \mathrm{H}$, (d) $\left(70 \mathrm{eV}\right.$, DCI probe) of $\mathrm{C}_{60} \mathrm{Me}_{6},(\mathbf{e})\left(70 \mathrm{eV}\right.$, DCI probe) of $\mathrm{C}_{60} \mathrm{Me}_{10}$, (f) (70 eV, DCI probe) of $\mathrm{C}_{60} \mathrm{Me}_{5} \mathrm{Cl}$. 

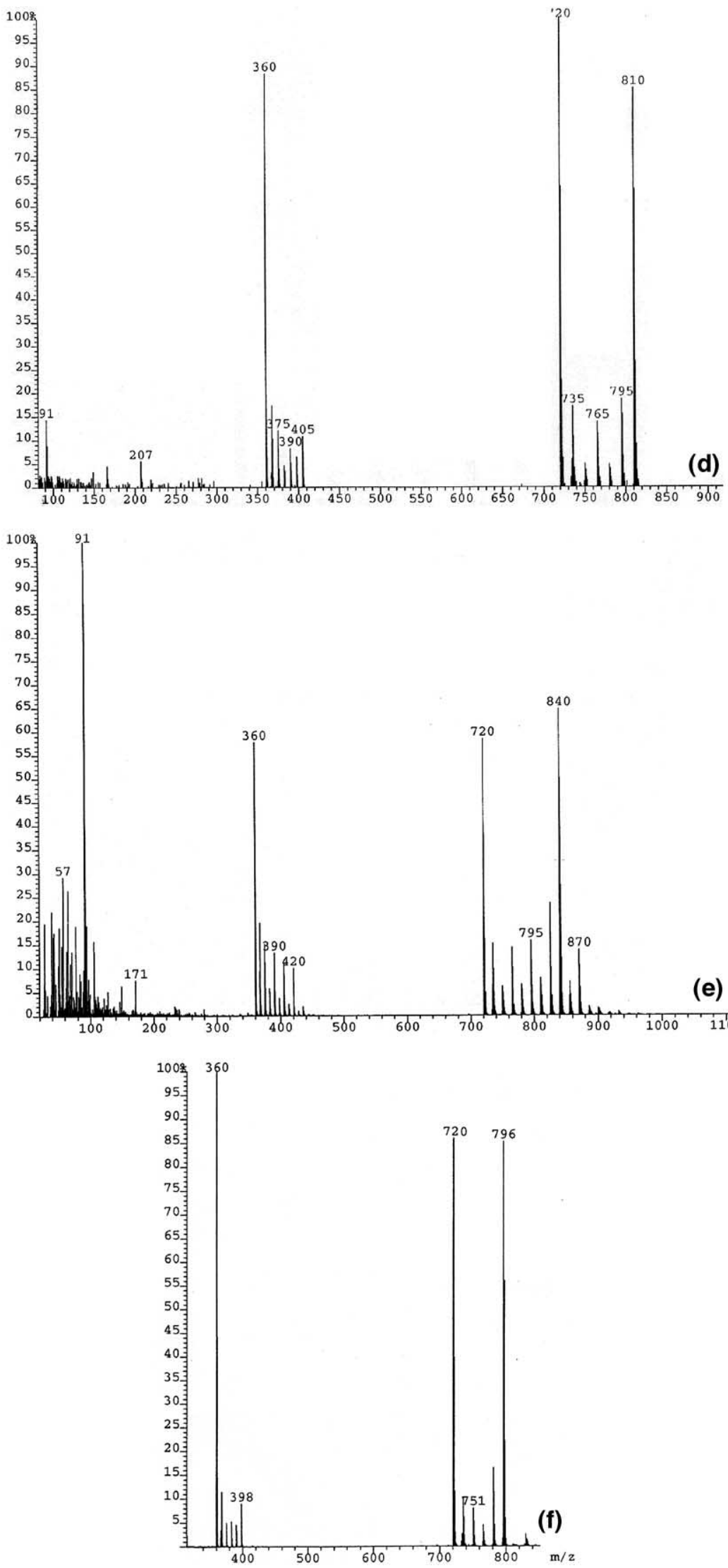

(e)

Figure 1. (continued) 


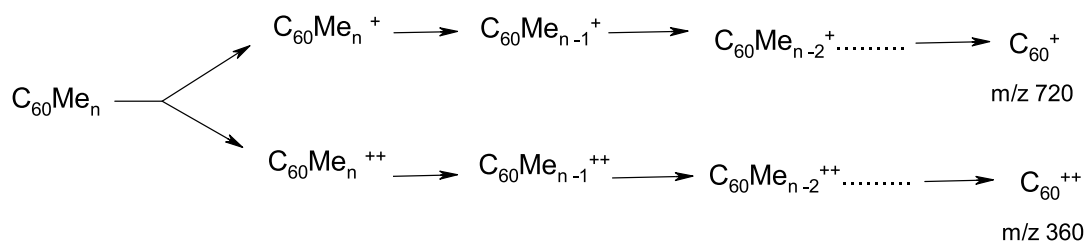

Scheme 1

Although the fullerene cage itself has been repeatedly subjected to a plethora of ionization techniques including EI, there have been comparatively few studies conducted to date that have studied the ionization of derivatized fullerenes, and few of these have achieved retention of exohedral functional groups, such as $\mathrm{CH}_{3}$, in an ionization techniques as "hard" as EI. Previous works have observed the additions of methyl radicals and hydrogen atoms to $\mathrm{C}_{60}$ in a mass spectrometer ion source because of the reactivity of fullerene in the gas-phase [6-8].

Figure 1a-f shows mass spectra of $\mathrm{C}_{60} \mathrm{Me}_{2}, \mathrm{C}_{60} \mathrm{Me}_{4}$, $\mathrm{C}_{60} \mathrm{Me}_{5} \mathrm{H}, \mathrm{C}_{60} \mathrm{Me}_{6}, \mathrm{C}_{60} \mathrm{Me}_{10}$, and $\mathrm{C}_{60} \mathrm{Me}_{5} \mathrm{Cl}$. The mass spectra of the methylated fullerenes, $\mathrm{C}_{60} \mathrm{Me}_{n}$, have the molecular ion peak $\mathrm{M}^{+}$, indicating that the product is stable under the mass spectrometry (EI) conditions. Two intense peaks are observed at $\mathrm{m} / \mathrm{z} 720$ and 360 corresponding to stable fragments of fullerene monocation $\mathrm{C}_{60}^{+}$and fullerene dication $\mathrm{C}_{60}^{2+}$, respectively. The weak peaks near $\mathrm{m} / \mathrm{z} 360$ correspond to successive loss of methyl groups from molecular dication $\left(\mathrm{M}^{2+}-\right.$ $\mathrm{nCH}_{3}$ ). The remaining peaks near $\mathrm{m} / z 720$ correspond to successive loss of methyl groups from molecular monocation $\left(\mathrm{M}^{+}-\mathrm{nCH}_{3}\right)$. Scheme $\mathbf{1}$ illustrates the fragmentation mechanism.

Mass spectrum of $\mathrm{C}_{60} \mathrm{Me}_{6}$ is an illustrative example as a typical for multimethylated fullerenes $\mathrm{C}_{60} \mathrm{Me}_{\mathrm{n}}$ (Figure 1d). The weak peaks at $m / z 367.5,375,382.5,390$, 397.5 , and 405 can only credibly be assigned to the singly to hextuply methylated $\mathrm{C}_{60}$ dication. All of these structures are seen in the singly charged fullerene higher-mass peaks also at $\mathrm{m} / \mathrm{z} 735,750,765,780,795$, and 810 , respectively.

It is observed that the singly charged methylated fragments bearing 1,3 , and 5 methyl groups are invariably more prominent than methylated fragments bearing 2, 4, and 6 methyls, whereas the reverse is true of the doubly charged ions in the same spectra. This could be interpreted in terms of open-shell versus closed-shell structures. The most abundant and stable $\mathrm{C}_{60} \mathrm{Me}_{n}^{+}$fragments ions with odd $n$ values are expected to be the closed-shell electronic configuration, whereas the most abundant and stable $\mathrm{C}_{60} \mathrm{Me}_{n}^{2+}$ fragments ions are expected to be the closed-shell electronic configuration with even $n$ values.

The prominent signal at $m / z 840$ in the spectrum of $\mathrm{C}_{60} \mathrm{Me}_{10}$ (Figure 1e) could be misinterpreted. For ion production by means of EI, it is difficult to distinguish between the fullerene ions and the various fragments ions with equal $\mathrm{m} / \mathrm{z}$, because all of these species are produced efficiently at similar high EI energies [9]. The $m / z 840$ peak could be $\mathrm{C}_{60} \mathrm{Me}_{8}^{+}$or $\mathrm{C}_{70}^{+}$or even a mixture of the two. The distinction was achieved by observing the signal of dication fullerene ions in the spectrum. The appearance of dication [60] fullerene $\mathrm{C}_{60}^{2+}$ at $\mathrm{m} / \mathrm{z} 360$ and the absence of dication [70] fullerene $C_{70}^{2+}$ in the same spectrum indicated that the $\mathrm{m} / \mathrm{z} 840$ is indeed $\mathrm{C}_{60} \mathrm{Me}_{8}^{+}$.

Previous experimental data on fullerene ionization has established that multiple ionization of $\mathrm{C}_{60}$ is readily achievable by EI or collision-induced ionization [9-12]. The doubly, triply, and quadruply charged hydrogenated fullerenes were efficiently detected [13]. This ability to undergo multiple ionization under routine EI conditions more closely resembles the features observed for pure fullerenes [13, 14]. The formation of dications has been established for fluorofullerenes [15], while any efficient multiple ionization of organic ligand bearing fullerenes has not been reported [13].

\section{Acknowledgments}

The authors thank the Research Administration, Kuwait University, for supporting this work under research grant SC07/02.

\section{References}

1. Al-Matar, H.; Abdul-Sada, A. K.; Avent, A. G.; Fowler, P. W.; Hitchcock, P. B.; Rogers, K. M.; Taylor, R. Isolation and characterization of symmetrical $\mathrm{C}_{60} \mathrm{Me}_{6}, \mathrm{C}_{60} \mathrm{Me}_{5} \mathrm{Cl}$ and $\mathrm{C}_{60} \mathrm{Me}_{5} \mathrm{O}_{2} \mathrm{OH}$, together with unsymmetrical $\mathrm{C}_{60} \mathrm{Me}_{5} \mathrm{O}_{3} \mathrm{H}$, $\mathrm{C}_{60} \mathrm{Me}_{5} \mathrm{OOH}, \mathrm{C}_{60} \mathrm{Me}_{4} \mathrm{PhO}_{2} \mathrm{OH}$, and $\mathrm{C}_{60} \mathrm{Me}_{12}$. J. Chem. Soc. Perkin Trans. 2002, 2, 53-58.

2. Al-Matar, H.; Hitchcock, P. B.; Avent, A. G.; Taylor, R. Isolation and characterization of $\mathrm{C}_{\mathrm{s}}$-symmetry $\mathrm{C}_{60} \mathrm{Me}_{5} \mathrm{O}_{2} \mathrm{OH}$, the first methylated fullernol; a bis-epoxide with two oxygens in a pentagonal ring. Chem. Commun. 2000, 1071-1072.

3. Al-Matar, H.; Abdul Sada, A. K.; Avent, A. G.; Taylor R.; Wei, X. Methylation of [70]fullerene. J. Chem. Soc. Perkin Trans. 2002, 2, 1251-1256.

4. Al-Matar, H.; Taylor, R. Methylation of [60]- and [70]fullerene. Electrochem. Soc. Proc. 1999, 163, 99-12.

5. Cotter, R. J. Mass spectrometry of nonvolatile compounds; desorption from extended probes. Anal. Chem. 1980, 52, 1589A-1606A.

6. Olah, G. A.; Bucsi, I.; Aniszefld R.; Surya Prakash, G. K. Chemical reactivity and functionalization of $\mathrm{C}_{60}$ and $\mathrm{C}_{70}$ fullerenes. Carbon. 1992, 30(8), 1203-1211.

7. Guo, X.; Liu Z.; Liu, S. Gas-phase ion-molecule reactions of buckminsterfullerene $\left(\mathrm{C}_{60}\right)$ with $\mathrm{Si}\left(\mathrm{CH}_{3}\right)_{n} \mathrm{Cl}_{4-n}(\mathrm{n}=2,3)$ in mass spectrometry. Chin. Chem. Lett. 1993, 4(9), 797-800. 
8. Shilova, E. A.; Lyakhovetskii, Y. I.; Tumanskii, B. L.; Belokon, A. I.; Belokon Y. N.; Nekrasov, Y. S. Alkylation and phenylation of [60]- and [70]-fullerenes by the reaction with ketones in the ionization chamber of a mass spectrometer. Mendeleev Commun. 1999, 9(5), 176-177.

9. Aumayr, F.; Vana, M.; Winter, H. P.; Drexel, H.; Grill, V.; Senn, G.; Matt, S.; Scheier P.; Mark, T. D. Distinction between multicharged fullerene ions and their fragment ions with equal charge-to-mass. Int. J. Mass Spectrom. Ion Process. 1997, 163, 9L-14L.

10. Jensen, J.; Zettergren, H.; Schmidt, H. T.; Cederquist, H.; Tomita, S.; Nielsen, S. B.; Rangama, J.; Hvelplund, P.; Manil, B.; Huber, B. A. Ionization of $\mathrm{C}_{70}$ and $\mathrm{C}_{60}$ molecules by slow highly charged ions: A comparison. Phys. Rev. A. 2004, 69, 053203-053204.

11. Scheier, P.; Dünser, B.; Senn, G.; Drexel, H.; Winter, H.P.; Aumayr, F.; Betz, G.; Biasioli, F.; Fiegele T.; Märk, T. D.
Stability of multiply charged fullerene ions. Eur. Phys. J. D. 1999, 9, 91-94.

12. Itoh, A.; Tsuchida, H.; Miyabe, K.; Majima, T; Imanishi, N. Ionization cross sections of $\mathrm{C}_{60}$ by fast electron impact. J. Phys. B. 1999, 32, 277-286.

13. Moder, M.; Nuchter, M.; Ondruschka, B.; Czira, G.; Vekey, K.; Barrow, M. P.; Drewello, T. Unimolecular ion dissociation and laser-induced coalescence of hydrogenated fullerene. Int. J. Mass Spectrom. 2000, 195/196, 599-607.

14. Steger, H.; de Vries, J.; Kamke, B.; Kamke, W.; Drewello, T. Ionization and fragmentation dynamics of highly flourinated fullerenes $\mathrm{C}_{60} \mathrm{~F}_{46,48}$ and $\mathrm{C}_{70} \mathrm{~F}_{54,56}$ after excitation with synchrotron radiation. Chem. Phys. Lett. 1997, 276, $39-46$.

15. Boltalina, O.V.; Borschevskii, A.Y.; Sidorov, L.N.; Street J.M.; Taylor, R. Preparation of $\mathrm{C}_{60} \mathrm{~F}_{36}$ and $\mathrm{C}_{70} \mathrm{~F}_{36 / 38 / 40}$. J. Chem. Soc. Chem. Commun. 1996, 529-530. 